\title{
Incidence and management of symptomatic dry eye related to LASIK for myopia, with topical cyclosporine $A$
}

This article was published in the following Dove Medical Press journal: Clinical Ophthalmology

\section{Anastasios John \\ Kanellopoulos ${ }^{1,2}$ \\ 'Laservision.gr Clinical and Research Eye Institute, Athens, Greece; ${ }^{2} \mathrm{NYU}$ Medical School, New York, NY, USA}

\section{Video abstract}

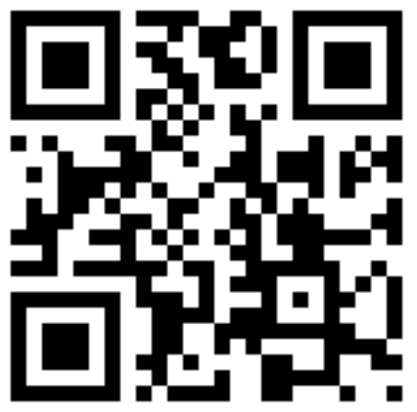

Point your SmartPhone at the code above. If you have a QR code reader the video abstract will appear. Or use: http://youtu.be/qagDvUDJdcg

Correspondence: Anastasios John Kanellopoulos Laservision.gr Clinical and Research Eye Institute, 17 Tsocha Street, Athens, I I52।, Greece

Tel +30210 7472777

Fax +302107472789

Email ajkmd@mac.com
Purpose: To evaluate the incidence of transient dry eye associated with LASIK for myopia and the efficacy of topical cyclosporine A administration.

Methods: Group A was formed from 145 ( 82 female, 63 male) eyes that developed clinically significant dry eye within 1 month post-LASIK and were subjected to cyclosporine A treatment. A "non-symptomatic for dry eye" and age- and gender-matched group (group B) was formed from the same pool of patients to serve as control. Schirmer's, tear film break-up time (TBUT) and Ocular Surface Disease Index (OSDI) questionnaire were evaluated. Central corneal epithelial thickness (CET) and topographic epithelial thickness variability (TVT) were evaluated as quantitative dry eye objective markers. Subjective patient survey was also assessed.

Results: Mean age was 39.7 \pm 6.2 years for the female and $47.67 \pm 9.5$ years for the male patients, in group A. Schirmer's test mean preoperative value was $8.4 \pm 3.1 \mathrm{~mm}$; and $4.5 \pm 3.6 \mathrm{~mm}$ at $1 \mathrm{month}$ post-LASIK. Statistically significant decrease from 1 month post-LASIK baseline was found at 12 months $(8.2 \pm 2.1 \mathrm{~mm} ; P=0.02)$. Mean preoperative TBUT value was $7.5 \pm 2.5$ seconds, $6.5 \pm 3.1$ seconds at 1 month postoperatively, and $7.6 \pm 2.0$ seconds at 12 months postoperatively, statistically significant to baseline $(P=0.04)$. Preoperatively, CET was $52.37 \pm 3.40 \mu \mathrm{m}$ and TTV was $1.24 \pm 0.57 \mu \mathrm{m}, 59.87 \pm 3.89 \mu \mathrm{m}$, and $2.74 \pm 0.57 \mu \mathrm{m}$ at 1 month post-LASIK respectively and at 12 months, $55.42 \pm 2.75 \mu \mathrm{m}$ and $1.39 \pm 0.96 \mu \mathrm{m}$. The differences in CET between 12 months post-LASIK vs baseline were statistically significant $(P=0.007)$. The mean preoperative OSDI scores were $11.47 \pm 9.97$ for group $\mathrm{A}$ and $11.79 \pm 10.31$ for group $\mathrm{B}(P=0.782)$, which changed to $23.03 \pm 10.17$ and $15.13 \pm 9.49$ at 12 months postoperatively $(P<0.05)$, respectively. Following commencement of cyclosporine A treatment in group A, statistically significant improvement was noted, greater than the one in group B, in all metrics at the 12-month examination in comparison to the 1-month baseline.

Conclusion: Topical cyclosporine A treatment is an effective alternative in the management of LASIK for myopia-related transient dry eye. Optical coherence tomography epithelial mapping may provide an objective benchmark in diagnosing and monitoring this significant disorder and its correlation with visual symptoms.

Keywords: LASIK-related dry eye, Restasis, cyclosporine A, epithelial thickness mapping, epithelial thickness variability, anterior segment OCT, AS-OCT

\section{Introduction}

Cyclosporine $\mathrm{A}$ is an immune-modulating drug which has been traditionally used in medicine in organ transplantation to prevent rejection. ${ }^{1}$ It is composed of a cyclic nonribosomal peptide of eleven amino acids and contains a single D-amino acid. ${ }^{2}$ The drug is known to suppress the immune system by interfering with T-cells' cycle progression. ${ }^{3}$ 
Dry eye $e^{4,5,30}$ is a multifactorial disease of the tears and ocular surface that results in symptoms of discomfort, visual disturbance, and tear film instability with potential damage to the ocular surface..$^{6-8}$ It is accompanied by increased tear film osmolarity and ocular surface inflammation. ${ }^{9-11}$ Dry eye is responsible for significant population morbidity and is a common clinical problem. ${ }^{12,13}$ Besides the significant symptoms and the detrimental effect on the quality of life, dry eye may present significant challenges in the evaluation of a refractive surgery candidate..$^{14,15}$

The alleviation of syndromes related to dry eye is among the applications of cyclosporine $\mathrm{A}$ in ophthalmology. ${ }^{16,17}$ Topical cyclosporine A emulsion is currently the only US Food and Drug Administration (FDA)-approved prescription drug for the treatment of inflammation in dry eye. Since 2002, a topical (0.05\%) cyclosporine emulsion has been marketed under the trade name Restasis (Allergan Inc., Irvine, CA, USA). ${ }^{18}$ The effectiveness of this drug for the treatment of inflammation associated with dry eye has been demonstrated. ${ }^{19-22}$ However, few studies have addressed the effects of topical cyclosporine A treatment in patients with dry eye before and after corneal refractive surgery. ${ }^{23-25}$ The purpose of this work was to analyze effects on eyes receiving topical cyclosporine A for clinically significant dry eye following LASIK for myopia surgery.

\section{Materials and methods}

This retrospective, non-randomized case series study received approval from the Ethics Committee of our Institution (Laservision.gr Clinical and Research Eye Institute), adherent to the tenets of the Declaration of Helsinki. Informed written consent was obtained from each subject at the time of the decision to be subjected to this therapy.

\section{Inclusion/exclusion criteria}

The study groups were derived from a pool of 1,250 consecutive patients who received primary LASIK intervention for the correction of myopia, including possible astigmatism. Study group A was formed from patients who reported postoperative dry eye problems at 1 month following the intervention according to the Ocular Surface Disease Index (OSDI) questionnaire by scoring a value of 33 or higher. One hundred and forty-five (145) patients fulfilled the criteria to be prescribed topical cyclosporine A ophthalmic solution $0.05 \%$ (one drop in each eye twice a day) beginning 1-month postoperatively. The duration of treatment application, as well as the clinical follow-up was 12 months. If a patient was lost to follow-up, he/she was withdrawn from the study group.
A non-symptomatic dry eye control group B was formed from the same pool of patients. Inclusion criteria for this group were the lack of patient report of significant postoperative dry eye-related problems according to the OSDI, specifically a score of 32 or lower at 1 month following the intervention, following clinical verification of this claim. The eyes in group $B$ were selected because they received the same examination protocols as those in group A.

Our current LASIK for myopia surgical technique has been described in detail in previous publications. ${ }^{26-28}$ In our clinical setting for a potential LASIK procedure, inclusion criteria are: no ocular pathology other than refractive error, no previous ocular surgery, documented refractive stability for at least 3 years, and suspension of contact lens use (if existing) for at least 2 weeks. Additional inclusion criteria were minimum subject age of 18 years, refractive spherical error up to $-8.00 \mathrm{D}$, astigmatism of 0.00 up to $-3.00 \mathrm{D}$, and central corneal thickness of at least $500 \mu \mathrm{m}$. In the patients studied herein all LASIK for myopia procedures involved a femtosecond laser-created flap (FS200 Femtosecond Laser, Alcon Laboratories Inc., Fort Worth, TX, USA), which was programmed to $8.00 \mathrm{~mm}$ diameter and $110 \mu \mathrm{m}$ thickness (our standard settings for LASIK for myopia). ${ }^{29}$ The myopic ablation was accomplished by the EX500 excimer laser (Alcon/WaveLight). Our exclusion criteria for LASIK are systemic or ocular diseases, history of corneal dystrophy or herpetic eye disease, topographic evidence of ectatic corneal disorder/keratoconus, epithelial warpage from contact lens use, glaucoma, severe dry eye, Sjögren syndrome, disorder of lid aperture, and allergies.

\section{Measurements}

All patients underwent a detailed ophthalmic examination including best corrected distance visual acuity (CDVA), uncorrected distance visual acuity (UDVA), and manifest refractive error in sphere, cylinder, and spherical equivalent (SE) before and after cycloplegia with two drops of $1 \%$ tropicamide topical solution, auto-refraction/keratometry with the Speedy-i-K model (Righton, Tokyo, Japan), slit lamp bio-microscopy, Scheimpflug camera tomography (WaveLight Oculyzer II, Alcon Laboratories Inc.), applanation tonometry, and dilated fundus exam to include retina periphery. Keratometric values (K1 and $\mathrm{K} 2$ ) and minimum pachymetry values were derived from the Pentacam (Oculus Optikgerate GmbH, Wetzlar, Germany). The measures of corneal thickness and the epithelial profiling were done using the anterior segment optical coherence tomography (AS-OCT) system RTVue ${ }^{\circledR} 100$ (Optovue Inc., Fremont, 
CA, USA). All patients underwent these tests preoperatively and at 1 day, 3 days, 1 week, 1 month, and 3, 6, and 12 months postoperative follow-up examinations. Measurement of tear film break-up time (TBUT), Schirmer's lacrimation test, and administration of the OSDI questionnaire, a validated questionnaire that measures the severity of dry eye disease, were conducted from the 1-month follow-up visit.

The Schirmer's lacrimation test results were expressed in mm wetting of the paper after 5 minutes following instillation of topical anesthesia of $0.1 \%$ proparacaine solution (Alcaine, Laboratories Inc.). The TBUT was reported in seconds following drop of fluorescein in the eye.

Epithelial thickness maps were obtained by non-contact AS-OCT in order to access a potential sensitive criterion for normal and dry eye, as we have previously reported. ${ }^{4,32}$ The Fourier-domain AS-OCT system RTVue-100 (Optovue Inc.) was employed to provide 3-dimensional epithelial thickness maps. ${ }^{31-33}$ For this study we evaluated the central epithelial thickness (CET), as well as the topographic variability of the epithelial thickness map. Both of these metrics are provided automatically by the system report. CET value was the mean epithelial thickness over the central $2 \mathrm{~mm}$ zone, and was obtained numerically by the epithelial thickness maps (examples of which are illustrated in Figure 1). The topographic epithelial thickness variability (TVT) is reported by the system software as well, in the form of the SD of the
17 individual thickness values over the epithelial map. CET and TVT are reported in micrometers.

The OSDI questionnaire ${ }^{53}$ was employed for the qualitative assessment of subjective perception of dry eye condition. Patients were requested to grade improvement of dry eye symptoms (pain or soreness, blurred vision, difficulty with reading, night driving, working with a computer, and difficulty in windy environment, areas with low humidity or areas that are air-conditioned) on a scale from 0 (no symptoms in the week before the test) to 4 (symptoms all the time in the week prior to the test). A final score was calculated ranging from 0-100 with scores $0-12$ representing normal, 13-22 representing mild dry eye disease, 23-32 representing moderate dry eye disease, and $<33$ representing severe dry eye disease. ${ }^{34}$ The same questions were asked at each visit and improvement was assessed by comparison.

All patients were postoperatively treated with moxifloxacin (Vigamox; Alcon Laboratories Inc.) and 0.1\% dexamethasone/chloramphenicol solution (Dispersadron C; Alcon Laboratories Inc.) four times a day in each eye (for both eye-drops) during the first week.

All possible adverse effects or patient complaints were closely monitored. At each follow-up visit the outcome assessors, such as optometrists and research assistants, as well as the patients themselves, remained masked to the assigned treatment, in order to improve objectivity and minimize potential bias.
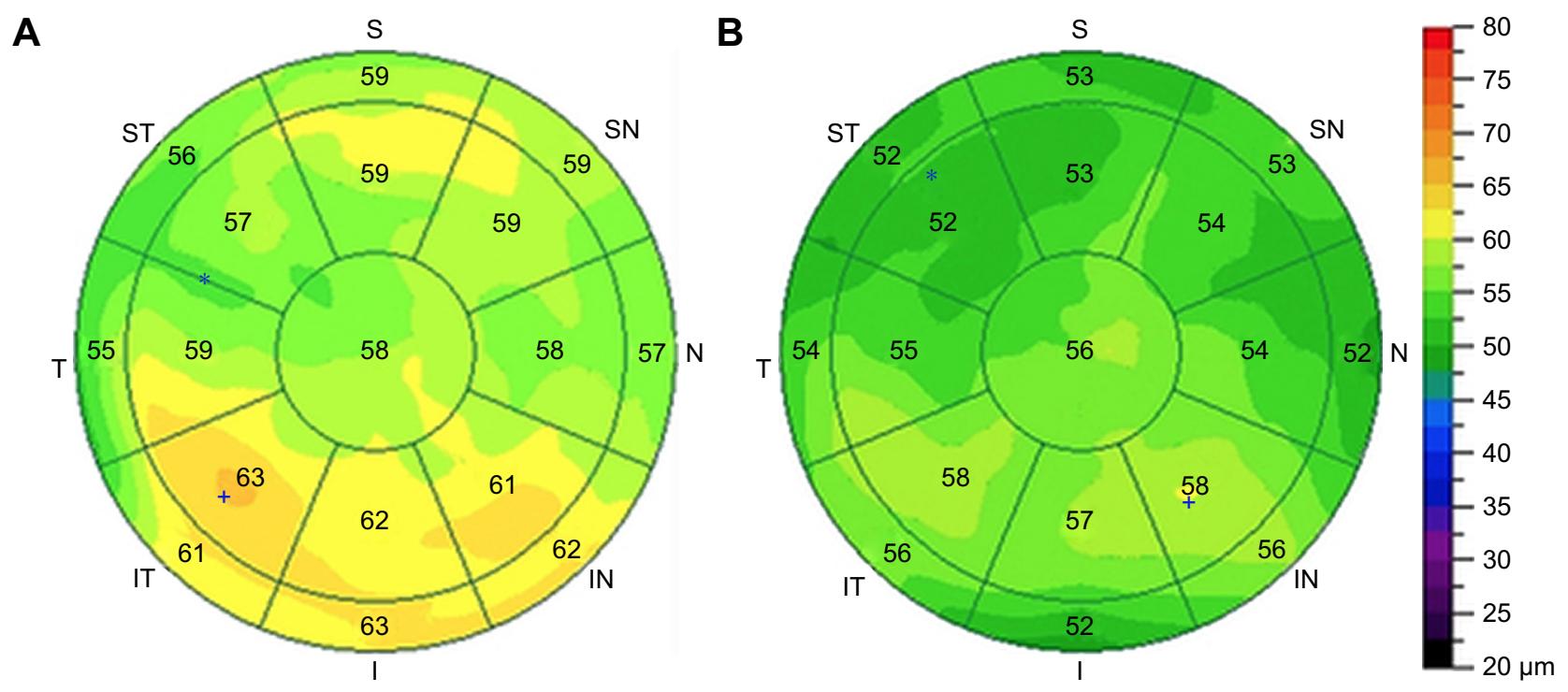

Figure I A representative case from group A, a transient dry eye LASIK patient.

Notes: (A) A representative epithelial map in a 43 year old female at month I following LASIK for myopia. Central epithelial thickness was 58 um and significant epithelial variability is noted $(S D=3.1 \mu \mathrm{m}$ ). Schirmer's was down to $5.5 \mathrm{~mm}$ from $8 \mathrm{~mm}$ preoperatively, and TBUT down to 4 seconds from 7 seconds preoperatively. (B) The same epithelial map at postoperative month 6 ( 5 months following treatment with cyclosporine A). Central epithelial thickness is reduced to $56 \mu$ m, and epithelial thickness variability to $2.1 \mu \mathrm{m}$. Schirmer's is up to $7 \mathrm{~mm}$ and TBUT is 7 seconds.

Abbreviation: TBUT, tear film break-up time. 
Statistical analysis was performed with Minitab version 16.2.3 (Minitab Ltd, Coventry, UK) and Origin Lab version 9 (OriginLab Corp, Northampton, MA, USA). Continuous and categorical variables were presented as mean \pm SD and analyzed by Pearson's chi-squared test. Paired analysis with $P<0.05$ was considered an indication of statistically significant results.

\section{Results}

The following samples were obtained from a pool of 1,250 consecutive patients who received LASIK for myopia. Preoperatively, mean SE was $-5.34 \pm 2.41 \mathrm{D}$ (range: -0.75 to -8.00 ) and cylinder $-1.03 \pm 0.93 \mathrm{D}$ (range: 0.00 to -3.25 ). Mean UDVA was $0.03 \pm 0.01$ logMAR (range: -0.2 to 0.2 ) and mean CDVA was $0.06 \pm 0.06 \operatorname{logMAR}$ with a range of -0.1 to 0.2 .

The dry eye study group, group A, was formed from 145 patients. Gender distribution was 82 female to 63 male patients. Mean patient age was $39.7 \pm 6.2$ years old (range: 29-57 years) for the female, and 47.67 \pm 9.5 years old (range: 35-65 years) for the male patients.

Mean preoperative Schirmer's lacrimation test value was $8.4 \pm 3.1 \mathrm{~mm}$ (range: $6-14$ ) and TBUT was $7.5 \pm 2.5$ seconds (range: $6-12$ ). Mean CET was $52.37 \pm 3.40 \mu \mathrm{m}$ (range: $43-66$ ) and mean TVT was $1.24 \pm 0.57 \mu \mathrm{m}$ (range: $0.6-3.4$ ). Adverse events were noted in one female patient, who dropped out due to stinging/burning sensation.
The control group, group B, was formed from 165 patients, 98 females (mean age $38.2 \pm 7.8$ years old; range: $26-43$ ) and 67 males (mean age 49.23 \pm 8.2 years old; range: $31-50$ ). Mean preoperative Schirmer's lacrimation test value was $8.9 \pm 3.5 \mathrm{~mm}$ (range: $7-16$ ) and TBUT was $8.5 \pm 2.9$ seconds (range: $7-17$ ). CET was $51.87 \pm 4.21 \mu \mathrm{m}$ (range: $42-61$ ) and TVT was $1.48 \pm 0.88 \mu \mathrm{m}$ (range: $0.8-2.9$ ).

Preoperative patient demographics are shown in Table 1, while all transient data regarding dry eye evaluation between the two groups are reported in Table 2. The preoperative and postoperative refractive characteristics were found not to be statistically significant.

The mean preoperative OSDI scores were 11.47 \pm 9.97 for group A and 11.79 \pm 10.31 for group B and not statistically different between them $(P=0.782)$. These values postLASIK, changed to $52.51 \pm 9.83$ and $20.11 \pm 9.76$ at 1 month $(P<0.01)$ and to $23.03 \pm 10.17$ and $15.13 \pm 9.49$ at 12 months postoperatively $(P<0.05)$, respectively. There were significant differences between the two groups of participants for their OSDI scores at 1 month postoperatively; this difference subsided significantly over the next months.

In the dry eye group, group A, at 1 month post-LASIK (commencement of cyclosporine A treatment), the mean Schirmer's lacrimation test value was $4.5 \pm 3.6 \mathrm{~mm}$ (range: 3-8). At 6 months post-LASIK, the mean Schirmer's lacrimation test result was $8.3 \pm 1.8 \mathrm{~mm}$ (range: $7-13$ ), and at 12 months post-LASIK, $8.2 \pm 2.1 \mathrm{~mm}$ (range: 7-13).

Table I Preoperative patient demographical data

\begin{tabular}{|c|c|c|c|c|c|}
\hline \multicolumn{6}{|c|}{ Preoperative patient demographics } \\
\hline \multirow[t]{2}{*}{ Variables } & \multicolumn{2}{|c|}{ Group A (n=|45) } & \multicolumn{2}{|c|}{ Group B $(n=165)$} & \multirow[t]{2}{*}{$P$-value } \\
\hline & Mean \pm SD & Range & Mean \pm SD & Range & \\
\hline Gender (F/M) & $82 / 63$ & - & $98 / 67$ & - & - \\
\hline Age (female) & $39.7 \pm 6.2$ & $29-57$ & $38.2 \pm 7.8$ & $26-43$ & 0.064 \\
\hline Age (male) & $47.67 \pm 9.5$ & $35-65$ & $49.23 \pm 8.2$ & $31-50$ & 0.122 \\
\hline UDVA (logMAR) & $0.04 \pm 0.08$ & $-0.2-0.2$ & $0.02 \pm 0.1$ & $-0.1-0.2$ & 0.055 \\
\hline CDVA (logMAR) & $0.07 \pm 0.05$ & $-0.1-0.2$ & $0.06 \pm 0.05$ & $-0.1-0.2$ & 0.080 \\
\hline MRSE (D) & $-5.2 I \pm 2.01$ & -1.25 to -7.75 & $-5.47 \pm 2.73$ & -0.75 to -8.00 & 0.346 \\
\hline Ablation depth $(\mu \mathrm{m})$ & $88.47 \pm 39.03$ & $29.0-214.2$ & $85.31 \pm 45.04$ & $31.0-205.7$ & 0.414 \\
\hline Optical zone (mm) & $6.68 \pm 0.24$ & $6.5-7.0$ & $6.72 \pm 0.26$ & $6.5-7.0$ & 0.162 \\
\hline CET $(\mu \mathrm{m})$ & $52.37 \pm 3.40$ & $43-66$ & $51.87 \pm 4.21$ & $42-61$ & 0.255 \\
\hline TVT $(\mu \mathrm{m})$ & $1.24 \pm 0.57$ & $0.6-3.4$ & $1.48 \pm 0.88$ & $0.8-2.9$ & 0.103 \\
\hline Schirmer $(\mathrm{mm})$ & $8.4 \pm 3.1$ & $6-14$ & $8.9 \pm 3.5$ & $7-16$ & 0.187 \\
\hline TBUT (s) & $7.5 \pm 2.5$ & $6-12$ & $8.5 \pm 2.9$ & $7-17$ & 0.053 \\
\hline
\end{tabular}

Notes: Group A received cyclosporine A treatment, initiated at I month following LASIK; group B served as a control group. The $P$-values in this table were not statistically significant $(P<0.05)$. There is no statistically significant difference in preoperative patient demographical data between the two groups (Group A \& Group B).

Abbreviations: CDVA, corrected distance visual acuity; CET, central epithelial thickness; MRSE, mean refractive spherical equivalent; TVT, topographic epithelial thickness variability; TBUT, tear film break-up time; UDVA, uncorrected distance visual acuity. 


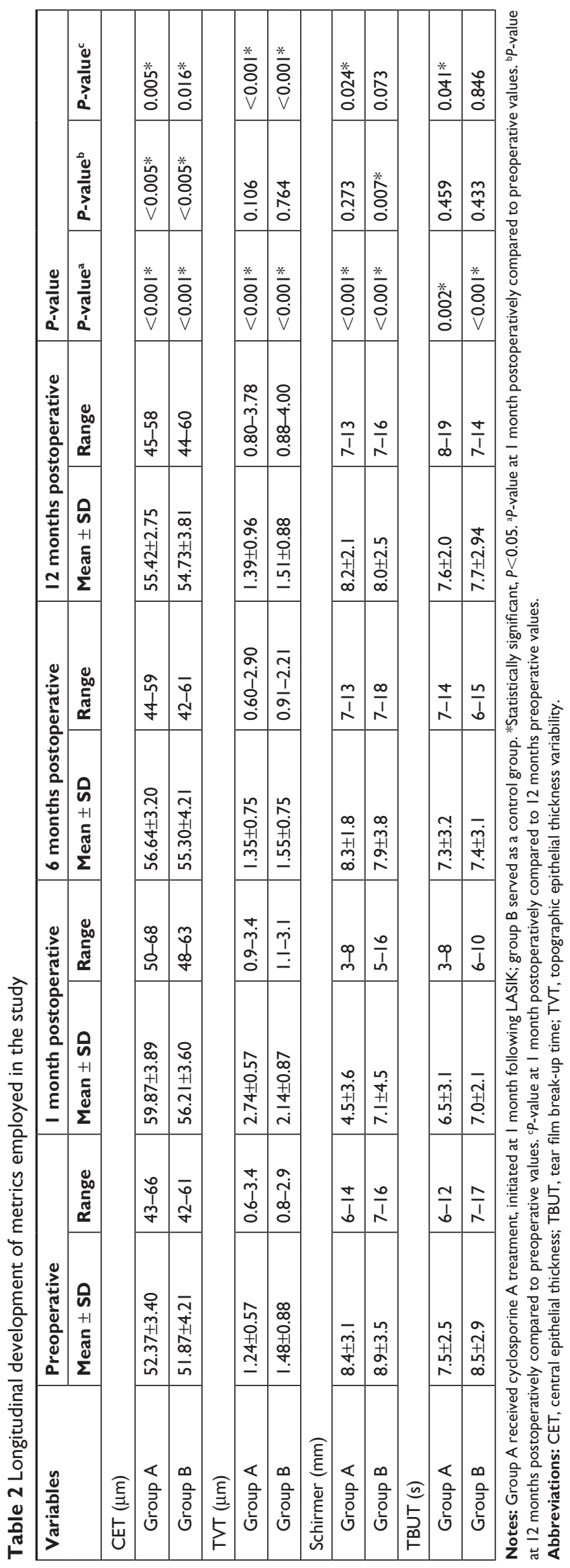

The differences in Schirmer's test results between 12 months vs 1 month (commencement of treatment) were statistically significant $(P=0.024)$. The differences between 6 months and 12 months vs preoperative were not statistically different $(P=0.151$ and $P=0.273)$.

At 1 month post-LASIK (commencement of cyclosporine A treatment) mean TBUT value was $6.5 \pm 3.1$ seconds (range: 3-8). At 6 months, mean TBUT was $7.3 \pm 3.2$ seconds (range: 7-14), and at 12 months, 7.6 \pm 2.0 seconds (range: $8-19$ ). The differences in TBUT results between 12 months vs 1 month (commencement of treatment) were statistically significant ( $P=0.041$ ). The differences between 6 months and 12 months vs preoperative were not statistically different $(P=0.397$ and $P=0.459$ ).

In the control group, group B, at 1 month post-LASIK, the mean Schirmer's lacrimation test value was $7.1 \pm 4.5 \mathrm{~mm}$ (range: 5-16). At 6 months post-LASIK, the mean Schirmer's lacrimation test result was $7.9 \pm 3.8 \mathrm{~mm}$ (range: 7-18), and at 12 months post-LASIK, $8.0 \pm 2.5 \mathrm{~mm}$ (range: $7-16$ ). The differences in Schirmer's test results between the final 12-month vs the 1-month or the intermediate 6-month evaluation period were not statistically significant $(P=0.073$ and $P=0.811$ ).

At 1 month post-LASIK mean TBUT value was 7.0 2.1 seconds (range: $6-10$ ). At 6 months, mean TBUT was 7.4 \pm 3.1 seconds (range: $6-15$ ), and at 12 months, $7.7 \pm 2.94$ seconds (range: 7-14). The differences in TBUT results between 12-month vs the initial 1-month and the intermediate 6-month evaluation were not statistically significant ( $P=0.846$ and $P=0.639$ ).

In group A 1 month postoperatively, mean CET was $59.87 \pm 3.89 \mu \mathrm{m}$ (range: $50-68$ ) and mean TVT $2.74 \pm 0.57 \mu \mathrm{m}$ (range: 0.9-3.4). Six months postoperatively, CET was $56.64 \pm 3.20 \mu \mathrm{m}$ (range: $44-59$ ), and TVT $1.35 \pm 0.75 \mu \mathrm{m}$ (range: 0.60-2.90). One year postoperatively, CET was $55.42 \pm 2.75 \mu \mathrm{m}$ (range: 45-58), statistically significant compared to preoperative mean value $(P<0.005)$ and TVT $1.39 \pm 0.96 \mu \mathrm{m}$ (range: $0.80-3.78$ ). The differences in CET between 6 months vs the 1-month baseline (commencement of treatment), as well as between 12 months vs the 1-month baseline were statistically significant $(P=0.005$ and $P=0.007$ ). The differences in TVT showed an initial increase at 1 month, which stabilized to near baseline at 6 and 12 months (not statistically significant compared to preoperative mean value, $P=0.106$ ).

In group B, CET at 1 month postoperatively was $56.21 \pm 3.60 \mu \mathrm{m}$ (range: $48-63$ ), at 6 months $55.30 \pm 4.21 \mu \mathrm{m}$ (range: $42-61$ ), and at 1 year $54.73 \pm 3.81 \mu \mathrm{m}$ (range: $44-60$ ). 
The differences in CET between 12 months to 6 months and 1 month were not statistically significant; however, the difference of $+2.86 \mu \mathrm{m}$ compared to baseline was statistically significant $(P=0.016)$. The differences in TVT showed an initial increase at 1 month $(2.14 \pm 0.87 \mu \mathrm{m}$; range: $1.1-3.1)$, which stabilized to near baseline at $6(1.55 \pm 0.75 \mu \mathrm{m}$; range: $0.91-2.21)$ and 12 months (1.51 $\pm 0.88 \mu \mathrm{m}$; range: 0.88-4.00).

Figure 1 illustrates a representative case from group A, a transient dry eye LASIK patient. The epithelial maps and other parameters prior to cyclosporine A treatment (Figure 1A) improved dramatically after several months of cyclosporine A treatment (Figure 1B).

\section{Discussion}

Some of the risk factors for dry eye syndrome include older age and female gender (postmenopausal estrogen therapy), medications (antihistamines), connective tissue disease, low intake of omega-3 essential fatty acids, as well as LASIK and refractive excimer laser surgery. ${ }^{9}$ Regarding LASIK surgery, although pre-existing dry eye may be subclinical, a sizable proportion of LASIK patients may develop consequences of reduced basal tear flow, ${ }^{35}$ attributed to severing of corneal neural innervation by the creation of the LASIK flap, ${ }^{36}$ and possibly by the excimer laser ablation. ${ }^{37} \mathrm{Clinical}$ evidence suggests that the alteration of corneal nerves due to LASIK is the most likely the cause of the subjective symptoms of LASIKinduced dry eye..$^{38}$ Both the literature-reported findings, ${ }^{39,40}$ as well as our clinical experience support that corneal sensitivity and clinical indicators of dry eye return to apparently normal values within a year, possibly due to partial recovery of the corneal nerve plexus. ${ }^{41,42}$ Other factors, such as alterations in conjunctival goblet cell density, might also contribute to the symptoms and clinical signs of LASIK-induced dry eye..$^{43-45}$

Acknowledging the importance of surgically-induced dry eye, we clinically evaluate all LASIK-treated patients thoroughly for related symptoms. We have been prescribing cyclosporine A treatment to all patients identified with dry eye severity that warrants management, following the initial 1-month scheduled visit. Follow-up lasts at least 1 year, according to our protocol, which involves numerous postoperative diagnostic tests, such as Vario Placido-based topography and AS-OCT.

Cyclosporine A belongs to a group of immunoregulatory compounds that were first isolated in Norway from the fungus Tolypocladium inflatum. ${ }^{46}$ These drugs exert their effects essentially by lowering the activity of T-cells, thereby suppressing the associated immune response. Because of their anti-rejection effects, both cyclosporine A and tacrolimus have been used in transplant patients. As the two drugs are largely similar in their ability to prevent acute rejection, practitioners often choose between these drugs based on their respective interactions with other medications a transplant patient may be prescribed. ${ }^{47}$ Topical ocular surface application of cyclosporine A has been suggested for postoperative photorefractive keratectomy and laser in situ keratomileusis. ${ }^{48-51}$ It must be noted, however, that the relevant effects of cyclosporine A on symptoms and signs may require several months of application and maximum effect is reached in 6 months. ${ }^{19,21,52}$

The results reported in this study document an improvement in post-LASIK dry eye following cyclosporine A treatment for up to 1 year postoperatively (11 months of treatment). Schirmer's lacrimation and TBUT tests employed in the study indicated dry eye-related symptoms increased at 1 month following LASIK and developed a declining trend following the treatment, returning to non-statistically significant differences when compared to the preoperative baseline levels. While a noted improvement was also present in the control group, group B, the findings herein suggest that at 1 year postoperatively, the cyclosporine A-treated group, group A, had an improvement at an average of $30 \%$ of most of the indicators employed for the assessment of dry eye, while the "naturally" occurring improvement in group B was of the order of $10 \%$.

We have included traditional as well as novel, possibly more objective dry eye assessment measurements, as well as subjective patient input.

The OCT-derived epithelial thickness and variability investigation may present an objective alternative to correlating dry eye condition, and offer the opportunity of documenting the results of the treatment. Specifically, the clinical difference of increased epithelial thickness reported in these studies, in comparison to healthy cohorts, ${ }^{32}$ was suggested as an important element in clinical practice acting as a "flag" for more specific dry eye investigation. ${ }^{4}$ The possible remodeling of epithelial analysis provides an objective way of evaluating the effects of dry eye, as well as the effectiveness of treatment(s) applied. Such were the noted decrease of epithelial thickness from an average of $59.87 \pm 3.89 \mu \mathrm{m}$ 1 month postoperatively (commencement of cyclosporine A treatment) to $56.64 \pm 3.20 \mu \mathrm{m} 6$ months postoperatively and $55.42 \pm 2.75 \mu \mathrm{m} 12$ months postoperatively.

This metric offers a comparison to the "naturally" occurring epithelial thickness and topographic variability increase following LASIK intervention. We have previously reported ${ }^{31}$ that 1 month following LASIK for myopia intervention, an average of $+1.58 \mu \mathrm{m}$ of CET increase compared to preoperative levels was observed; this increase (which may or may 
not be related to dry eye) appears to remain constant, as this increase is on average $+1.42 \mu \mathrm{m} 1$ year postoperatively. In the present study, the epithelial thickness compared to preoperative levels was substantially increased just prior to cyclosporine A treatment $(+7 \mu \mathrm{m})$. This may be a clear indication of documenting the dry eye condition objectively. In addition, the epithelial thickness difference appeared to be consistently smaller, to $+4 \mu \mathrm{m}$ at 6 months and to $+3 \mu \mathrm{m}$ at 1 year postoperatively ( 11 months into the cyclosporine $\mathrm{A}$ treatment). While a residual epithelial thickness increase was noted, it was comparable to the $+2 \mu \mathrm{m}$ found in the study of LASIK for myopia remodeling, ${ }^{31}$ which may be attributed simply to either the curvature changes or to the reduced biomechanical stability, both induced by the LASIK procedure. The epithelial thickness investigation presented in this study clearly indicated a return to "comparable" or even more reduced thickness to non-dry eye LASIK population. Many patients who present for screening for surgery may be effectively optimized with this diagnostic methodology for surgery to improve important measures such as aberrometry used in custom excimer laser ablation and to decrease the incidence and severity of dry eye symptoms and signs after surgery.

Similar improvements were noted when using the "traditional" measurement techniques of dry eye, such as the Schirmer's and TBUT tests. However, there is much debate about the clinical usefulness due to accuracy of these subjective tests, as there are many variations and a large degree of subjectivity involved. In general, it can probably be assumed that while a Schirmer's may produce a false "normal" result, a low score on a Schirmer's test is a clear indication that there is in fact an aqueous deficiency. In addition, the Schirmer's test results do not correlate with tear quality, only quantity, and should not be relied upon exclusively in attempting to measure dry eye, both because of its limited reliability and because of the limited scope of what it is measuring (only aqueous tear production).

Of considerable note may be the significant gender and age correlation to the occurrence of clinically significant dry eye following LASIK for myopia. Women are affected almost four times more commonly, and men at an older age. These findings may help the clinician in the decision-making of the optimal suggested surgical treatment for myopic correction in females vs males and in correlation to patient age.

\section{Conclusion}

The results of this study demonstrate that topical $0.05 \%$ cyclosporine $\mathrm{A}$ is effective in treating transient postoperative dry eye that may develop following LASIK for myopia in patients who did not have preoperative symptoms or signs of dry eye. AS-OCT epithelial imaging may provide adjuvant objective assessment for diagnosis and disease improvement under treatment.

\section{Disclosure}

The author reports no conflicts of interest in this work.

\section{References}

1. Chen J, Zmijewska A, Zhi D, Mannon RB. Cyclosporine-mediated allograft fibrosis is associated with micro-RNA-21 through Akt signaling. Transpl Int. 2015;28(2):232-245.

2. Flechner SM. Cyclosporine: a new and promising immunosuppressive agent. Urol Clin North Am. 1983;10(2):263-275.

3. Cantrell DA, Smith KA. The interleukin-2 T-cell system: a new cell growth model. Science. 1984;224(4655):1312-1316.

4. Kanellopoulos AJ, Asimellis G. In vivo 3-dimensional corneal epithelial thickness mapping as an indicator of dry eye: preliminary clinical assessment. Am J Ophthalmol. 2014;157(1):63-68.e2.

5. Taneri S, Oehler S, Asimellis G, Kanellopoulos AJ. Influence of corneal cross-linking for keratoconus on several objective parameters of dry eye. J Refract Surg. 2013;29(9):612-616.

6. Brignole F, Pisella PJ, Goldschild M, et al. Flow cytometric analysis of inflammatory markers in conjunctival epithelial cells of patients with dry eyes. Invest Ophthalmol Vis Sci. 2000;41(6):1356-1363.

7. Lemp MA. Advances in understanding and managing dry eye disease. Am J Ophthalmol. 2008;146(3):350-356.

8. Latkany R. Dry eyes: etiology and management. Curr Opin Ophthalmol. 2008;19(4):287-291.

9. Michael AL, Christophe B, Jules B, et al. The definition and classification of dry eye disease: report of the definition and classification Subcommittee of the International dry eye workshop (2007). Ocul Surf. 2007;5(2):75-92.

10. Pflugfelder SC, Wilhelmus KR, Osato MS, Matoba AY, Font RL. The autoimmune nature of aqueous tear deficiency. Ophthalmology. 1986;93(12):1513-1517.

11. Pflugfelder SC. Antiinflammatory therapy for dry eye. Am JOphthalmol. 2004;137(2):337-342.

12. Stern ME, Beuerman RW, Fox RI, et al. The pathology of dry eye: the interaction between the ocular surface and lacrimal glands. Cornea. 1998;17(6):584-589.

13. Solomon A, Dursun D, Liu Z, et al. Pro- and anti-inflammatory forms of interleukin-1 in the tear fluid and conjunctiva of patients with dry-eye disease. Invest Ophthalmol Vis Sci. 2001;42(10):2283-2292.

14. Li M, Gong L, Chapin WJ, Zhu M, et al. Assessment of vision-related quality of life in dry eye patients. Invest Ophthalmol Vis Sci. 2012;53(9): 5722-5727.

15. Baudouin C. The pathology of dry eye. Surv Ophthalmol. 2001; 45(Suppl 2):S211-S220.

16. Schultz C. Safety and efficacy of cyclosporine in the treatment of chronic dry eye. Ophthalmol Eye Dis. 2014;6:37-42.

17. Sahli E, Hoşal BM, Zilelioğlu G, Gülbahçe R, Ustün H. The effect of topical cyclosporine $\mathrm{A}$ on clinical findings and cytological grade of the disease in patients with dry eye. Cornea. 2010;29(12):1412-1416.

18. Perry HD, Donnenfeld ED, Kanellopoulos AJ, Grossman GA, et al. Topical cyclosporin A in the management of postkeratoplasty glaucoma. Cornea. 1997;16(3):284-288.

19. Perry HD, Solomon R, Donnenfeld ED, et al. Evaluation of topical cyclosporine for the treatment of dry eye disease. Arch Ophthalmol. 2008; 126(8):1046-1050.

20. Sahli E, Hoşal BM, Zilelioğlu G, Gülbahçe R, Ustün H. The effect of topical cyclosporine A on clinical findings and cytological grade of the disease in patients with dry eye. Cornea. 2010;29(12):1412-1416.

21. Sall K, Stevenson OD, Mundorf TK, Reis BL. Two multicenter, randomized studies of the efficacy and safety of cyclosporine ophthalmic emulsion in moderate to severe dry eye disease. CSA phase 3 study Group. Ophthalmology. 2000;107(4):631-639. 
22. Tsubota K, Saito I, Ishimaru N, Hayashi Y. Use of topical cyclosporin A in a primary Sjögren's syndrome mouse model. Invest Ophthalmol Vis Sci. 1998;39(9):1551-1559.

23. Peyman GA, Sanders DR, Batlle JF, Féliz R, Cabrera G. Cyclosporine $0.05 \%$ ophthalmic preparation to aid recovery from loss of corneal sensitivity after LASIK. J Refract Surg. 2008;24(4):337-343.

24. Salib GM, McDonald MB, Smolek M. Safety and efficacy of cyclosporine $0.05 \%$ drops versus unpreserved artificial tears in dry-eye patients having laser in situ keratomileusis. J Cataract Refract Surg. 2006; 32(5):772-778.

25. Ursea R, Purcell TL, Tan BU, et al. The effect of cyclosporine A (Restasis) on recovery of visual acuity following LASIK. $J$ Refract Surg. 2008;24(5):473-476.

26. Kanellopoulos J, Asimellis G. Long-term bladeless LASIK outcomes with the FS200 femtosecond and EX500 excimer laser workstation: the refractive suite. Clin Ophthalmol. 2013;7:261-269.

27. Kanellopoulos AJ, Asimellis G. Refractive and keratometric stability in high myopic LASIK with high-frequency femtosecond and excimer lasers. J Refract Surg. 2013;29(12):832-837.

28. Kanellopoulos AJ, Skouteris V, Soteriou Z. Topography-guided hyperopic and hyperopic astigmatism femtosecond laser-assisted LASIK: long-term experience with the $400 \mathrm{~Hz}$ eye-Q excimer platform. Clin Ophthalmol. 2012;6:895-901.

29. Kanellopoulos AJ, Asimellis G. Digital analysis in flap parameter accuracy and opaque bubble layer objective assessment in femtosecond laser assisted LASIK. A novel technique. Clin Ophthalmol. 2013;7:343-351.

30. Kanellopoulos AJ, Asimellis G. Reply. Am J Ophthalmol. 2014;157(5): 1116-1117.

31. Kanellopoulos AJ, Asimellis G. Longitudinal postoperative LASIK epithelial thickness profile changes in correlation with degree of myopia correction. J Refract Surg. 2014;30(3):166-171.

32. Kanellopoulos AJ, Asimellis G. In vivo three-dimensional corneal epithelium imaging in normal eyes by anterior-segment optical coherence tomography: a clinical reference study. Cornea. 2013;32(11): 1493-1498.

33. Kanellopoulos AJ, Asimellis G. Corneal epithelial remodeling following cataract surgery: three-dimensional investigation with anterior-segment optical coherence tomography. J Refract Surg. 2014;30(5):348-353.

34. Grubbs JR, Tolleson-Rinehart S, Huynh K, Davis RM. A review of quality of life measures in dry eye questionnaires. Cornea. 2014;33(2): 215-218.

35. Wilson SE. Laser in situ keratomileusis-induced (presumed) neurotrophic epitheliopathy. Ophthalmology. 2001;108(6):1082-1087.

36. Sun CC, Chang CK, Ma DH, et al. Dry eye after LASIK with a femtosecond laser or a mechanical microkeratome. Optom Vis Sci. 2013; 90(10):1048-1056.

37. Azuma M, Yabuta C, Fraunfelder FW, Shearer TR. Dry eye in LASIK patients. BMC Res Notes. 2014;7(1):420.
38. Toda I. LASIK and the ocular surface. Cornea. 2008;27(Suppl 1): S70-S76.

39. Golas L, Manche EE. Dry eye after laser in situ keratomileusis with femtosecond laser and mechanical keratome. J Cataract Refract Surg. 2011;37(8):1476-1480.

40. Ambrósio R, Tervo T, Wilson SE. LASIK-associated dry eye and neurotrophic epitheliopathy: pathophysiology and strategies for prevention and treatment. J Refract Surg. 2008;24(4):396-407.

41. Albietz JM, Lenton LM, McLennan SG. Effect of laser in situ keratomileusis for hyperopia on tear film and ocular surface. J Refract Surg. 2002; 18(2):113-123

42. Aras C, Ozdamar A, Bahcecioglu H, et al. Decreased tear secretion after laser in situ keratomileusis for high myopia. J Refract Surg. 2000; 16(3):362-364.

43. Chao C, Golebiowski B, Stapleton F. The role of corneal innervation in LASIK-induced neuropathic dry eye. Ocul Surf. 2014;12(1): $32-45$.

44. Jabbur NS, Sakatani K, O’Brien TP. Survey of complications and recommendations for management in dissatisfied patients seeking a consultation after refractive surgery. J Cataract Refract Surg. 2004; 30(9):1867-1874.

45. Toda I, Asano-Kato N, Hori-Komai Y, Tsubota K. Laser-assisted in situ keratomileusis for patients with dry eye. Arch Ophthalmol. 2002;120(8): 1024-1028.

46. Yagci A, Gurdal C. The role and treatment of inflammation in dry eye disease. Int Ophthalmol. 2014;34(6):1291-1301.

47. Zarrinpar A, Busuttil RW. Immunomodulating options for liver transplant patients. Expert Rev Clin Immunol. 2012;8(6):565-578.

48. Hessert D, Tanzer D, Brunstetter T, et al. Topical cyclosporine A for postoperative photorefractive keratectomy and laser in situ keratomileusis. J Cataract Refract Surg. 2013;39(4):539-547.

49. Erie JC, McLaren JW, Hodge DO, Bourne WM. Recovery of corneal subbasal nerve density after PRK and LASIK. Am J Ophthalmol. 2005;140(6):1059-1064.

50. Calvillo MP, McLaren JW, Hodge DO, Bourne WM. Corneal reinnervation after LASIK: prospective 3-year longitudinal study. Invest Ophthalmol Vis Sci. 2004;45(11):3991-3996.

51. Salomão MQ, Ambrósio R, Wilson SE. Dry eye associated with laser in situ keratomileusis: mechanical microkeratome versus femtosecond laser. J Cataract Refract Surg. 2009;35(10):1756-1760.

52. Dastjerdi MH, Hamrah P, Dana R. High-frequency topical cyclosporine $0.05 \%$ in the treatment of severe dry eye refractory to twice-daily regimen. Cornea. 2009;28(10):1091-1096.

53. Kagkelaris K. Study of the efficacy and side effects of original and branded medicines in the treatment of glaucoma. 2017. Available from: http://nemertes.lis.upatras.gr/jspui/bitstream/10889/10319/6/ Nemertes_Kagkelaris\%28chem\%29.pdf. Accessed February 15, 2019. Greek.
Clinical Ophthalmology

\section{Publish your work in this journal}

Clinical Ophthalmology is an international, peer-reviewed journal covering all subspecialties within ophthalmology. Key topics include: Optometry; Visual science; Pharmacology and drug therapy in eye diseases; Basic Sciences; Primary and Secondary eye care; Patient Safety and Quality of Care Improvements. This journal is indexed on Submit your manuscript here: http://www.dovepress.com/clinical-ophthalmology-journal
Dovepress

PubMed Central and CAS, and is the official journal of The Society of Clinical Ophthalmology (SCO). The manuscript management system is completely online and includes a very quick and fair peer-review system, which is all easy to use. Visit http://www.dovepress.com/ testimonials.php to read real quotes from published authors. 